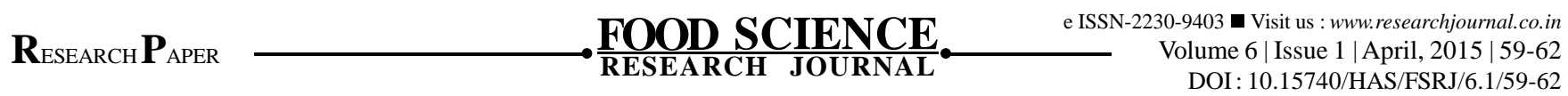

\title{
Prevalance of malnutrition among varanasi infants and its corelation with their socio-economic status
}

\author{
Anjali Mishra, Archana Chakravarty and O.P. Mishra
}

\begin{abstract}
The prevalence of underweight among infants in India is highest in the world. In India child malnutrition rates are higher even though income levels are higher and infant's mortality rates is lower. The present study is carried out on infants of Varanasi to find out their growth and nutritional status in the first year of life and their socio-economic status. It was a cross sectional survey carried out on infants of 3 to 12 months of age of Varanasi. For growth and nutritional status all anthropometric and clinical measurements were recorded by using standard techniques. Information regarding nutrient intake was recorded by using 24 hour dietary recall method and S.E.S was recorded by the pretested questionnaire. The result came that 66 per cent of Varanasi infants was malnourished and low S.E.S was one of the main factor for undernutrition among them. It is concluded that major cause of undernutrition is lack of knowledge about nutrition and breast feeding habits, poor economic conditions etc. For weaning infants starchy food would prefer most other than protein rich foods. Due to shortage of economy and production and preparation of baby foods the essential nutrient requirements of babies are not fulfilled. Therefore, it is needed to review our policies and proper nutrition education about pre-weaning and post-weaning habits should be given to the mothers.
\end{abstract}

Key Words : Malnutrition, S.E.S, Infants, Nutritional status, Growth

How to cite this article : Mishra, Anjali, Chakravarty, Archana and Mishra, O.P. (2015). Prevalance of malnutrition among varanasi infants and its corelation with their socio-economic status. Food Sci. Res. J., 6(1): 59-62.

Email: toanjalimishra@gmail.com

Associate Authors' :

ARCHANA CHAKRAVARTY, Department of Home Science (Food and

Nutrition), Banaras Hindu University, VARANASI (U.P.) INDIA

Email: archana.nutrition@gmail.com

O.P. MISHRA, Department of Pediatrics, Institute of Medical Sciences, Banaras

Email: opmpedia@yahoo.co.uk 